\title{
OPEN Study of spatial and temporal aging characteristic of catalyzed diesel particulate filter catalytic performance used for diesel vehicle
}

\begin{abstract}
Yun-hua Zhang ${ }^{\bowtie}$, Di-ming Lou ${ }^{\bowtie}$, Pi-qiang Tan \& Zhi-yuan Hu
Catalyzed diesel particulate filters (CDPFs) have been widespread used as a technically and economically feasible mean for meeting increasingly stringent emissions limits. An important issue affecting the performance of a CDPF is its aging with using time. In this paper, the effects of noble metal loadings, regions and using mileage on the aging performance of a CDPF were investigated by methods of X-ray diffraction (XRD), X-ray photoelectron spectroscopy and catalytic activity evaluation. Results showed that aging of the CDPF shifted the XRD characteristic diffraction peaks towards larger angles and increased the crystallinity, showing a slowing downward trend with the increase of the noble metal loadings. In addition, the increase of the noble metal loading would slow down the decline of $\mathrm{Pt}$ and $\mathrm{Pt}^{4+}$ concentration caused by aging. The characteristic temperatures of $\mathrm{CO}$, $\mathrm{C}_{3} \mathrm{H}_{8}$ conversion and $\mathrm{NO}_{2}$ production increased after aging, and the more the noble metal loadings, the higher the range of the increase. But noticeably, excessive amounts of noble metals would not present the corresponding anti-aging properties. Specifically, the degree of aging in the inlet region was the deepest, the following is the outlet region, and the middle region was the smallest, which were also reflected in the increase range of crystallinity, characteristic temperatures of $\mathrm{CO}, \mathrm{C}_{3} \mathrm{H}_{8}$ conversion and $\mathrm{NO}_{2}$ production, as well as the decrease range of $\mathrm{Pt}$ and $\mathrm{Pt}^{4+}$ concentrations. The increase of aging mileage reduced the size of the aggregates of the soot and ash in CDPFs, however, improved the degree of tightness between particles. Meanwhile Carbon (C) concentration in the soot and ash increased with the aging mileage.
\end{abstract}

Diesel engines have been widely used in urban buses and heavy-duty trucks throughout the world for their strong power, good economy and high reliability ${ }^{1,2}$. Although the electrification of vehicle is coming, for a long period of time in the future, the market for diesel engines will be continuously growing in China due in large part to higher fuel efficiency compared to gasoline engines ${ }^{3}$. However, exhaust emissions including carbon monoxide (CO), hydrocarbons (properly indicated as $\mathrm{CxHy}$, but typically expressed as $\mathrm{HC}$ ), especially large amounts of particulate matter has brought about critical environmental and healthy issues ${ }^{4}$, resulting in the implementation of restrictions on diesel exhaust particulate matter (PM) and NOx emissions ${ }^{5}$. To meet the increasing emission regulations, a combination of diesel oxidation catalyst (DOC) and diesel particulate filter (DPF) is used as an efficient diesel engine after-treatment technology ${ }^{6}$. The upstream DOC can oxidize the CO and HC, the downstream DPF can trap the particle emission with a high efficiency up to $90 \%$. The catalyzed diesel particulate filter (CDPF) manufactured by coating noble metal catalyst such as Pt and Pd et al. on the wall of DPF is being widely employed as an efficient diesel emission control technology ${ }^{7}$. It can not only oxidize CO, HC and increase the $\mathrm{NO}_{2}$ proportion by oxidizing $\mathrm{NO}^{8}$, but also filter the particles with a high efficiency ${ }^{9}$, and achieve a regeneration of the CDPF by oxidizing the trapped particles with a relatively low temperature ${ }^{10}$. The Pt and Pd have strong catalytic activity in oxidizing CO, HC and NO. More importantly, the Pt and Pd coated on the CDPF can substantially reduce the light-off temperature of the trapped soot from $450-550^{\circ} \mathrm{C}$ to $250-300{ }^{\circ} \mathrm{C}$ with the presence of $\mathrm{NO}_{2}$, which enables the CDPF to conduct a passive regeneration at the exhaust temperature of diesel engine without extra temperature improvement measures ${ }^{11}$. In addition, adding Pd or Rh into the Pt-based catalyst can inhibit the sintering of Pt particles during aging and promote the re-dispersion of Pt particles, improving the anti-aging ability of the CDPF. Consequently, noble metal catalyst including $\mathrm{Pt}, \mathrm{Pd}$ as well as $\mathrm{Rh}$, plays a key role

School of Automotive Studies, Tongji University, Shanghai 201804, China. ${ }^{\bowtie}$ email: zhangyunhua313@163.com; loudiming@tongji.edu.cn 


\begin{tabular}{|c|c|c|c|}
\hline \multirow[b]{2}{*}{ Item } & \multicolumn{3}{|c|}{ Parameter } \\
\hline & No.1 & No.2 & No.3 \\
\hline Substrate & \multicolumn{3}{|l|}{ Cordierite } \\
\hline Thickness $(\mathrm{mm})$ & \multicolumn{3}{|l|}{0.35} \\
\hline Cell density (cpsi) & \multicolumn{3}{|l|}{200} \\
\hline Porosity/\% & \multicolumn{3}{|l|}{55} \\
\hline Average pore diameter $(\mu \mathrm{m})$ & \multicolumn{3}{|l|}{$8-13$} \\
\hline Catalyst & \multicolumn{3}{|l|}{$\mathrm{Pt} / \mathrm{Pd} / \mathrm{Rh}$} \\
\hline Pt:Pd:Rh & \multicolumn{3}{|l|}{$10: 2: 1$} \\
\hline Catalyst loadings (g/L) & 0.53 & 0.71 & 1.24 \\
\hline Coatings & \multicolumn{3}{|l|}{$\gamma-\mathrm{Al}_{2} \mathrm{O}_{3}$} \\
\hline
\end{tabular}

Table 1. Specifications of CDPFs.

in the performance of the $\mathrm{CDPF}^{12}$. However, deterioration of catalyst used severely affects the performance of the $\mathrm{CDPF}^{13}$, leading to deactivate mechanisms including thermal aging ${ }^{14}$, chemical poisoning and mechanical damage $^{15}$. With the continuous upgrading of fuel, the sulfur content is very low $(\leq 10 \mathrm{ppm})$, causing less chemical poisoning of the catalyst ${ }^{16}$. Hence, thermal deactivation has always been the main reason for the deterioration of catalytic performance which is caused by the sintering and agglomeration of noble metal components as well as the sintering of washcoat surface area ${ }^{17}$. To investigate the deactivation of catalysts of the CDPF, different methods have been presented by scholars across the world. The cheapest and fastest method is thermal or hydrothermal oven ageing ${ }^{18}$, i.e. exposure to a constant high temperature for a defined time, but this method is not able to reflect the authentic aging process of the CDPF in real use ${ }^{19}$. On-engine durability test is also adopted to study the deterioration of catalytic performance, but there is no corresponding basis between the engine test time and the vehicle actually using mileage ${ }^{20}$. On-vehicle DPF durability evaluation is the most practicable even though this approach is typically time-consuming and, in many cases, cost prohibitive. Zhang et al. studied the deterioration performance of the CDPF based on an urban bus by monitoring the filter efficiency on particulate emissions with mileage, but further analysis about the changes in catalytic performance was not carried out in this study ${ }^{21}$. In fact, there are many factors affecting the deterioration of the CDPF catalytic activity, including noble metal loadings, the region in which catalyst is located and using mileage, et al. Liu et al. studied effects of coating on the performance of the CDPF and found that the increase in the amount of precious metal coated can improve its durability ${ }^{22}$. Tsuda et al. found that more Pt contained was efficient for enhancing the catalyst thermal durability ${ }^{23}$. Hauff et al. studied aging status of the catalyst with different Pt loadings and found that the catalytic activity is mainly related to the catalytically active surface which can be determined by Pt loadings ${ }^{24}$. Ren et al. found that the anti-aging characteristics of the catalyst increases with the precious metals loading coated, but excessive amounts of precious metals impair the anti-aging characteristics ${ }^{25}$. Except the precious metal loadings, $\mathrm{Pt} / \mathrm{Pd}$ ratio in the catalyst of the CDPF also has an effect on the catalyst's aging performance ${ }^{26}$. Besides, due to the effect of the exhaust flow and temperature, different regions in the CDPF presents different aging characteristics. Zhan et al. applied the on-engine tests to study durability of the DPF in different positions by monitoring the DPF thermal profiles of the inlet, mid-bed and rear-bed and found that the thermal shock is highest in the rear-bed of the $\mathrm{DPF}^{27}$. Bai et al. also found that the temperature peak appears at the rear-bed of the DPF, which will accelerate the aging of the coated catalyst ${ }^{28}$. The latest emission regulations put forward higher requirements for the durability of the $\mathrm{CDPF}^{29}$. The aging degree of the catalytic performance in the CDPF on-vehicle deepens with the using mileage, which can be reflected by the morphology and compositions of the soot and ash in the $\mathrm{CDPF}^{30}$. This can offer a new way for analyzing the effect of using mileage on the deterioration of CDPF. Although there have been many separate studies on the effects of noble metal loadings, regions or using mileage on the durability performance of CDPF, little studies were observed considering all the three influencing factors at the same time, especially using the method of on-vehicle aging. Therefore, this study aims to apply XRD, XPS and catalytic activity evaluation to analyze the effect of noble metal loadings on the durability performance of the CDPF using on-vehicle aging method. Meanwhile the aging characteristics of the CDPF in different regions were analyzed. Moreover, the microstructure and composition of the soot and ash in CDPFs with different aging mileage were investigated.

\section{Experimental method}

Specifications of CDPFs. In order to study the effect of noble metal loadings on the aging performance of CDPF, three different CDPFs were designed based on reference and engineering application experience ${ }^{8,31}$, and their specifications are shown in Table 1 . The noble metal loadings of the CDPFs are $0.53,1.71$ and $1.24 \mathrm{~g} / \mathrm{L}$, and named No.1, No.2 and No. No.3 respectively. The CDPFs all adopted passive regeneration ways, and they were aged on the same series of $7.1 \mathrm{~L}$ urban diesel buses.

Specifications of the vehicles. The designed CDPFs were installed on the same series buses, which were selected from a bus fleet on the same line. The main specifications of the buses were the same and they were presented in Table 2 . All the buses ran on a fixed line with a daily mileage of about $200 \mathrm{~km}$, and the transport 


\begin{tabular}{|l|l|}
\hline Parameter & Value \\
\hline Bus type & SUNWIN SWB6100V5 \\
\hline Curb weight $(\mathrm{kg})$ & 16,500 \\
\hline Engine type & Deutz D7E240 \\
\hline Capacity $(\mathrm{L})$ & 7.1 \\
\hline Maximum velocity $(\mathrm{km} / \mathrm{h})$ & 85 \\
\hline Rated power $(\mathrm{kW} / \mathrm{rpm})$ & $177 / 2300$ \\
\hline Maximum torque $(\mathrm{N} \mathrm{m} / \mathrm{rpm})$ & $920 / 1700$ \\
\hline Emission level & Euro III \\
\hline Model year & 2011 \\
\hline
\end{tabular}

Table 2. Main specifications of the buses.

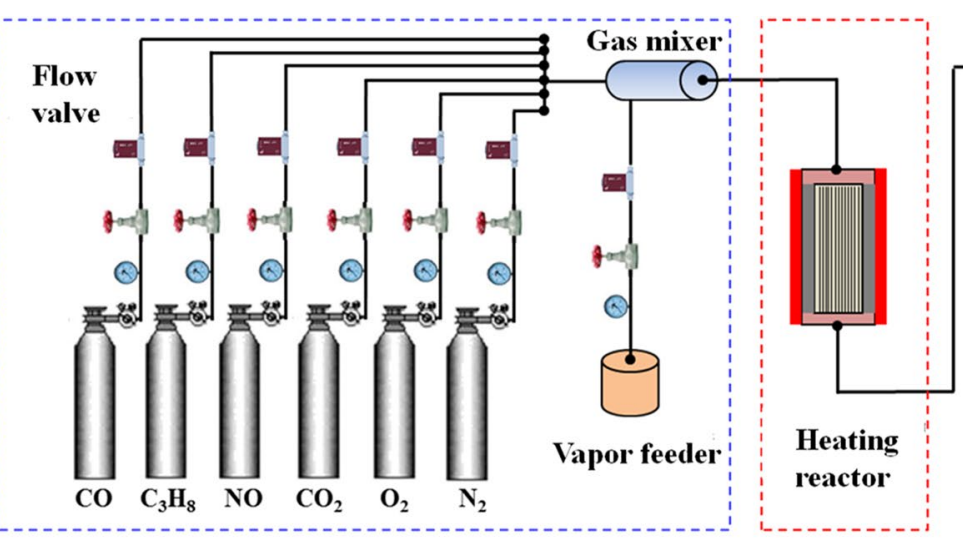

Gas supply unit
Reaction unit

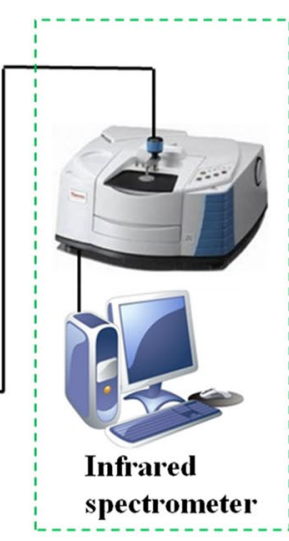

Analysis unit

Figure 1. Catalytic activity evaluation system.

load for every bus was almost the same during the mileage. Consequently, the effect of bus conditions, traffic and transport load on the passive regeneration degree of the CDPFs during the aging process were consistent.

Test methods and equipment. The XRD, XPS and catalytic activity evaluation were used to characterize the aging performance of the CDPFs. The XRD is a research method to obtain the information of material composition, internal atomic or molecular structure or morphology through the analysis of X-ray diffraction and diffraction patterns, which can accurately measure the crystal structure and crystal size ${ }^{32}$. The XPS is an effective method to measure the composition and chemical state of surface elements of the materials by quantitatively evaluating the binding energy peak intensity and peak displacement of different atoms or molecule ${ }^{33}$. The catalytic activity evaluation based on temperature-programmed reduction (TPR) system is an effective method to quantitatively analyze the catalytic activity of the catalyst ${ }^{34}$.

In this study, the XRD analysis was conducted to ascertain phase changes, crystallinity et al. of the CDPF samples by X ray diffractometer (D8 Advance, Bruker Axs Gmbh, Germany), the test accuracy is very high with angular reproducibility of $\pm 0.001^{\circ}$, and the test stability is $\pm 0.01 \%$. The XPS analysis based on X ray photoelectron spectroscopy (PHI 5000C ESCA, PerkinElmer, USA) was carried out to evaluate the components, valence and distribution of noble metal elements in CDPF samples, the test resolution of this instrument is $0.1 \%$ and the angular reproducibility reaches $\pm 0.001^{\circ}$. The TPR system is used to evaluate the catalytic activity of the CDPF samples, this system consists of a gas supply unit, reaction unit and analysis unit as shown in Fig. 1. The gas supply unit provided the $\mathrm{CO}, \mathrm{C}_{3} \mathrm{H}_{8}$ and $\mathrm{NO}$ components with concentration of $400,400,400 \mathrm{ppm}$, in addition, the $\mathrm{O}_{2}$ and $\mathrm{N}_{2}$ were provided as equilibrium gas. The saturated vapor was supplied from the vapor feeder, and the above gases were mixed through the gas mixer. Then the mixed gas entered the temperature-programmed heating reactor. The catalyst sample was input in the heating reaction and then analyzed by fourier transform infrared (FT-IR) spectrometer (Nicolet iS10, Thermofisher Scientific, USA), the resolution of this instrument reaches $0.0035 \mathrm{~cm}^{-1}$ and the test accuracy is $\pm 1 \%$. In addition, the scanning electron microscope (SEM) and energy dispersive spectroscopy (EDS) instrument (Quanta 250FEG, FEI, USA) was used to conduct a morphology analysis of the soot and ash sampled from the CDPF, as well as a semi-quantitative analysis of the elements.

Test program. When the CDPFs used for buses devices were prepared, the samples with the same catalyst parameters were also prepared. First, the fresh CDPF samples were cut into small samples with size of 


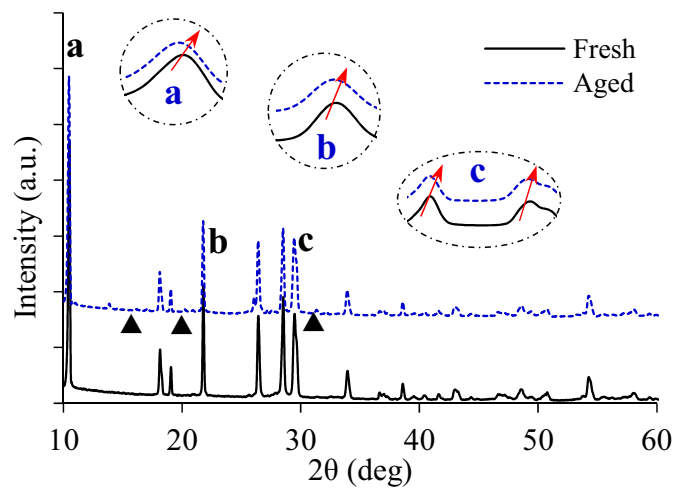

(a)

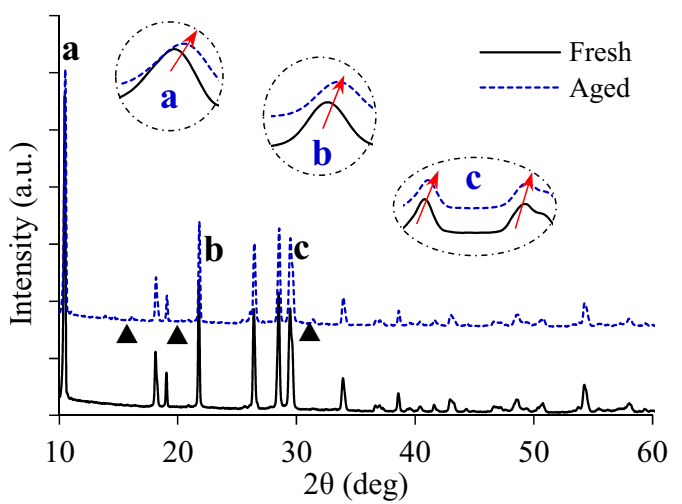

(b)

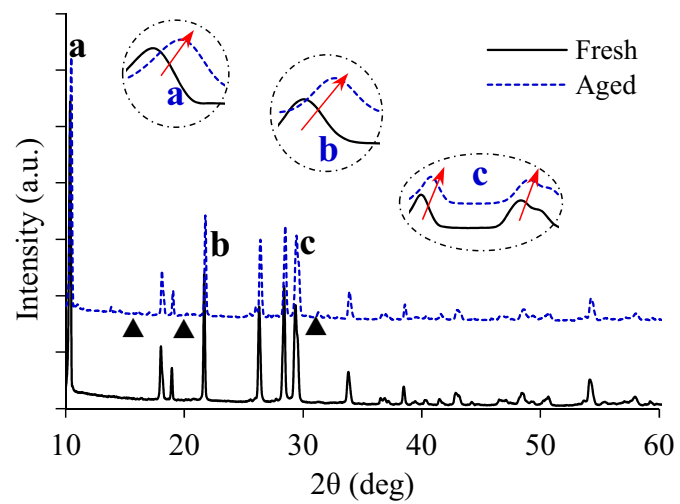

(c)

Figure 2. XRD results for fresh and aged CDPFs (a) No.1 CDPF, (b) No.2 CDPF, (c) No.3 CDPF.

$10 \mathrm{~mm} \times 10 \mathrm{~mm} \times 50 \mathrm{~mm}$, and the catalytic activity of the small samples were evaluated using TPR method. Meanwhile, the fresh CDPF samples were cut into small pieces to carry out the XRD and XPS tests. The standard CDPFs were installed to the same mode of buses. When the buses equipped with CDPFs run for about $30,000 \mathrm{~km}$, the soot and ash in the No.2 CDPF were sampled by reverse purge method $^{35}$, then the soot and ash were sampled for SEM test and energy dispersive spectrometer (EDS) test. When the buses run for 60,000 km, all the CDPFs were sampled with size of $10 \mathrm{~mm} \times 10 \mathrm{~mm} \times 50 \mathrm{~mm}$ in the central area by cutting method ${ }^{36}$, and the samples were tested using TPR to evaluate the catalytic activity. In addition, small pieces were also sampled for XRD and XPS tests. In addition, for No.2 CDPF, the soot and ash inside were also sampled by reverse purge method, and the soot and ash samples were used for SEM and EDS tests.

\section{Results and discussions}

The durability of the CDPFs with different noble metal loadings. In this part, the XRD, XPS and activity evaluation were carried out to analyze the durability of the CDPFs with different noble metal loadings.

XRD and crystallinity analysis. Figure 2 shows the XRD diffraction patterns of CDPFs before and after $60,000 \mathrm{~km}$ ' aging. It can be seen that the XRD diffraction patterns of No.1, No.2 and No.3 CDPFs were similar. The characteristic diffraction peaks (marking a, b, c) all occurred in the ranges of $10^{\circ}-11,17^{\circ}-22^{\circ}$ and $25^{\circ}-31^{\circ}$ for the three CDPFs. After the CDPFs were used for $60,000 \mathrm{~km}$, the peaks shifted towards large angles, which indicated that aging induced caused the lattice contraction of the sample and the reduction of the unit cell parameters. With the increase of the noble metal loadings, there was no obvious difference in the offset angle of XRD diffraction peaks. Besides, there were varying new peaks (marking filled triangle) for the aged CDPFs' XRD diffraction patterns, which illustrated the formation of new crystalline phases. The possible reason was that the dispersed noble metals and metal oxides formed crystals with poor crystalline phase during aging, resulting in a decrease of the catalytic activity ${ }^{37}$.

Figure 3 presents the crystallinity of the CDPFs from No.1 to No.3 before and after 60,000 km' durability based on the Debye-Scherrer calculation method ${ }^{38}$. It can be seen that the crystallinity of the CDPFs increased after aging. Especially for No.1 CDPF, the crystallinity increased from $77.24 \%$ to $78.79 \%$. While for No.2 and No.3 CDPFs, the increase of the crystallinity can be negligible. The increase of the crystallinity indicated that 


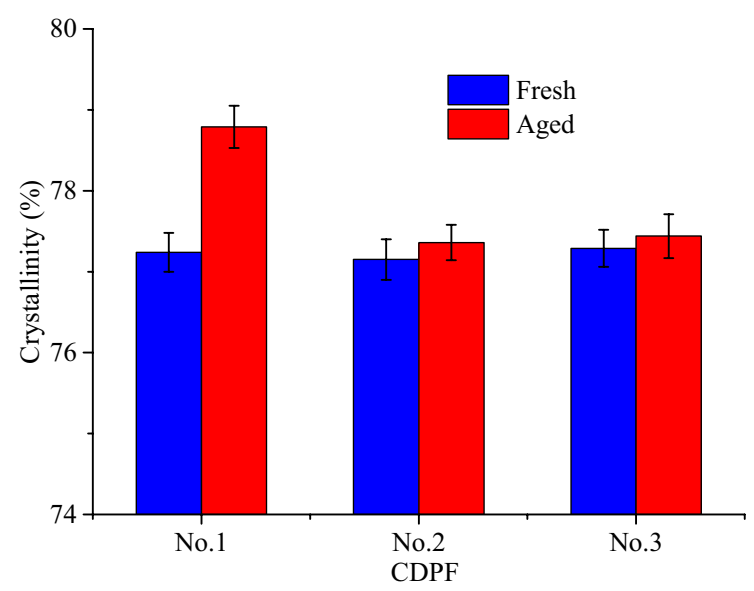

Figure 3. Crystallinity of the CDPFs before and after aging.

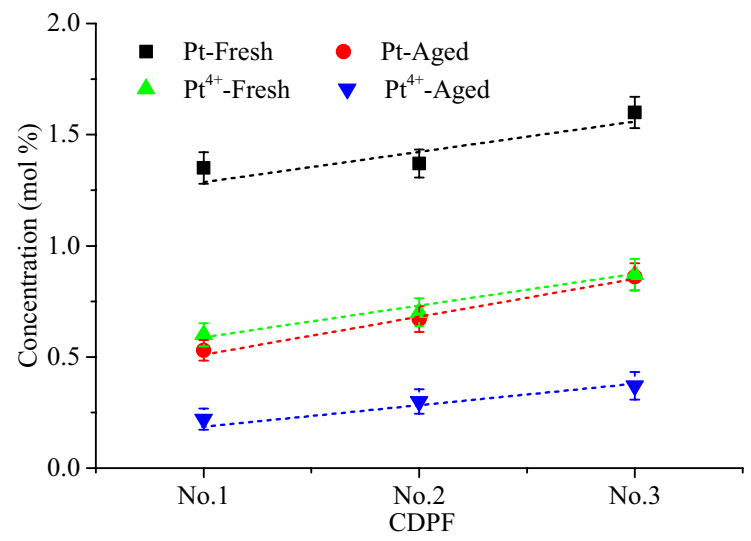

Figure 4. $\mathrm{Pt}$ and $\mathrm{Pt}^{4+}$ concentrations of fresh and aged CDPFs.

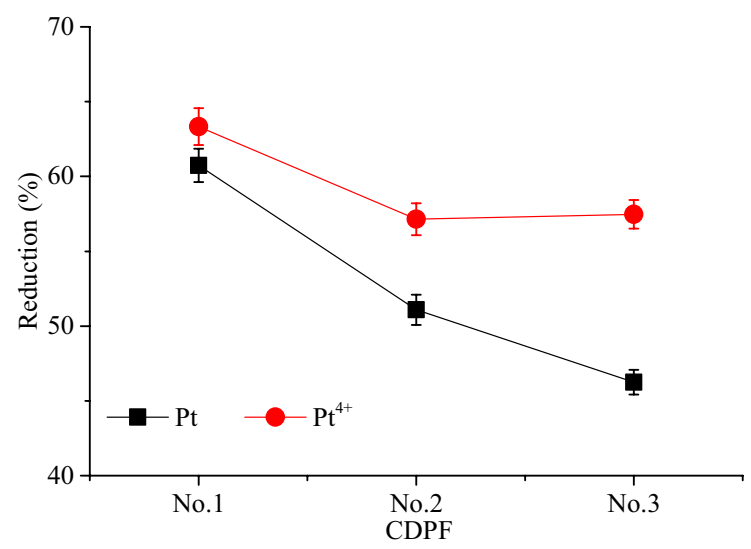

Figure 5. Reduction of $\mathrm{Pt}$ and $\mathrm{Pt}^{4+}$ concentrations of aged CDPFs.

new crystalline phase formed. On the other hand, the growing of the grain of the substrate and the crystalline type tending to be complete after aging may also increase the crystallinity ${ }^{39}$.

Active element and valence states analysis. The active elements $\mathrm{Pt}$ and $\mathrm{Pt}^{4+}$ concentrations shown in Fig. 4 were measured by XPS test. It can be seen that the Pt and $\mathrm{Pt}^{4+}$ concentrations increased linearly with the noble metal loadings. After aging, $\mathrm{Pt}$ and $\mathrm{Pt}^{4+}$ concentrations of the samples decreased significantly. Figure 5 presented the reduction of $\mathrm{Pt}$ and $\mathrm{Pt}^{4+}$ concentrations of the tress CDPFs after aging. It shown that the $\mathrm{Pt}$ and $\mathrm{Pt}^{4+}$ concentra- 


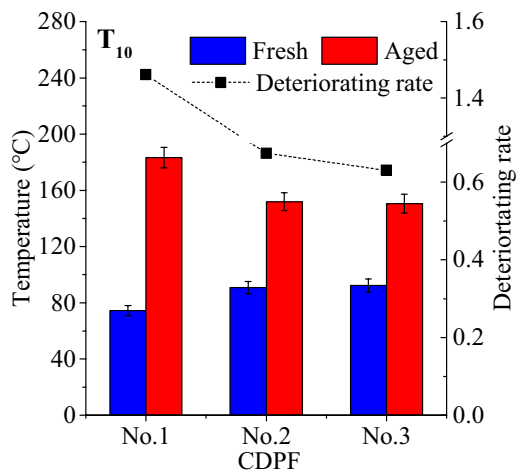

(a)

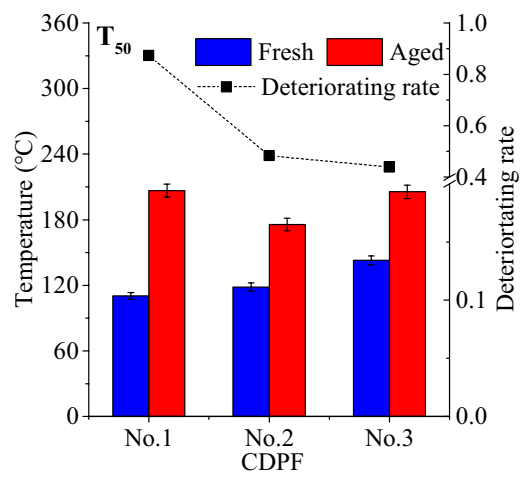

(b)

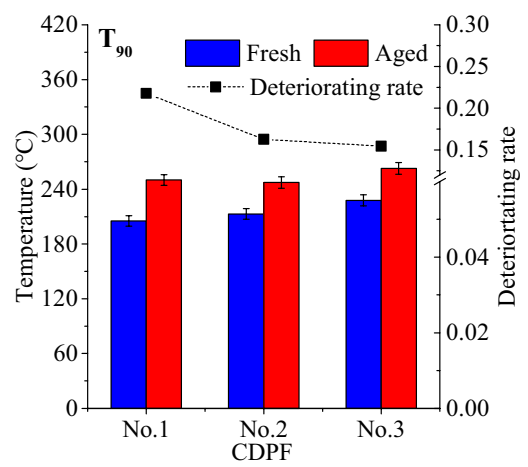

(c)

Figure 6. Characteristic temperatures and deteriorating rates of $10 \%, 50 \%$ and $90 \%$ CO conversion rates (a) $10 \%$ CO conversion rate $-\mathrm{T}_{10}$, (b) $50 \%$ CO conversion rate $-\mathrm{T}_{50}$, (c) $90 \%$ CO conversion rate $-\mathrm{T}_{90}$.

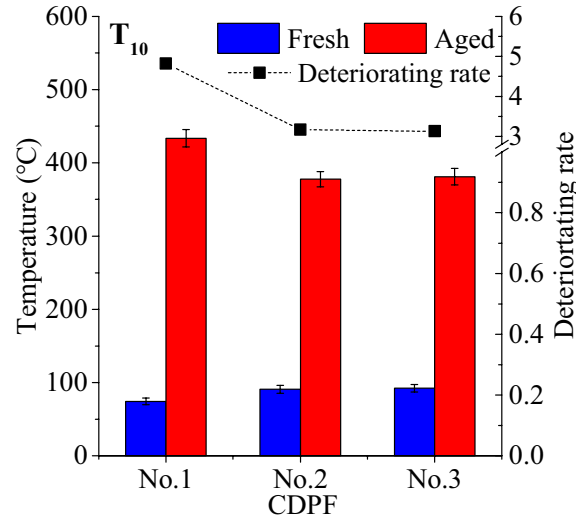

(a)

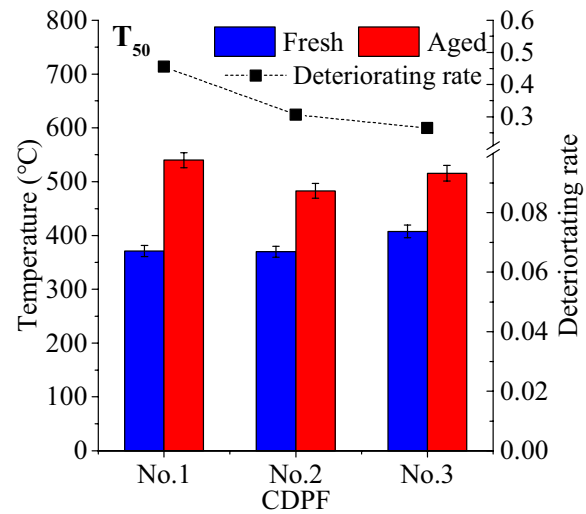

(b)

Figure 7. Characteristic temperatures and deteriorating rates of $10 \%$ and $50 \% \mathrm{C}_{3} \mathrm{H}_{8}$ conversion rates (a) $10 \%$ $\mathrm{C}_{3} \mathrm{H}_{8}$ conversion rate $-\mathrm{T}_{10}$, (b) $50 \% \mathrm{C}_{3} \mathrm{H}_{8}$ conversion rate $-\mathrm{T}_{50}$.

tions of No.1 CDPF decreased most of the three CDPFs, which reached $60.74 \%$ and $63.33 \%$, respectively. For No.2 and No.3 CDPFs, the decreases of $\mathrm{Pt}$ and $\mathrm{Pt}^{4+}$ concentrations were nearly the same, but obviously, lower than that of No.1. Since the catalytic activity of the catalyst is directly related to the concentration of the noble metal, the results of active element and valence states analysis indicated that the higher the noble metal loadings, the slower the degradation of the CDPF catalytic performance.

Catalytic activity evaluation. In this part, the catalytic activities of CDPFs were studied by analyzing the temperatures corresponding to the conversion rates of $\mathrm{CO}, \mathrm{C}_{3} \mathrm{H}_{8}$ and production rate of $\mathrm{NO}_{2}$ by CDPFs. The degradation rate of the catalytic properties of CDPFs is defined as:

$$
\text { Deteriorating rate }=\frac{T_{\text {aged }}-T_{\text {fresh }}}{T_{\text {aged }}} \times 100 \%
$$

where $T_{\text {aged }}$ presents the temperatures of the $\mathrm{CO}, \mathrm{C}_{3} \mathrm{H}_{8}$ conversion and $\mathrm{NO}_{2}$ production for aged CDPFs and $T_{\text {fresh }}$ means the temperatures of the $\mathrm{CO}, \mathrm{C}_{3} \mathrm{H}_{8}$ conversion and $\mathrm{NO}_{2}$ production for fresh CDPF.

Figure 6 presents characteristic temperatures and deteriorating rates of $10 \%, 50 \%$ and $90 \%$ CO conversion rates. The $\mathrm{T}_{10} \mathrm{~s}$ of the three CDPFs increased in different degrees. The more of the noble metal loadings, the lower of the deteriorating rate. But from No. 2 to No.3 CDPFs, the deteriorating rates decreased from 0.67 to 0.63 with little drop. The $\mathrm{T}_{50} \mathrm{~s}$ of CO for No.1, No.2 and No.3 CDPFs in fresh condition were $110.26,118.42$ and $142.83^{\circ} \mathrm{C}$ and they increased to $206.60,175.65$ and $205.55^{\circ} \mathrm{C}$ after $60,000 \mathrm{~km}$ ' aging with the deteriorating rates of 0.87 , 0.48 and 0.44 . The latter two had quite the same deteriorating rates, significantly lower than that of No.1 CDPF. For $\mathrm{T}_{90 \mathrm{~S}}$, they increased little after aging of the CDPFs. The deteriorating rates had a similar changing trend with the noble metal loadings as $\mathrm{T}_{50}$.

Figure 7 presents the Characteristic temperatures and deteriorating rates of $10 \%$ and $50 \% \mathrm{C}_{3} \mathrm{H}_{8}$ conversion rates. It can be seen that the $\mathrm{T}_{10} \mathrm{~S}$ of $\mathrm{C}_{3} \mathrm{H}_{8}$ for the three CDPFs were all below $100^{\circ} \mathrm{C}$, but they increased to 433.57 , 377.74 and $381.24^{\circ} \mathrm{C}$ for No.1, No.2 and No.3 CDPFs after aging with corresponding deteriorating rates of 4.82 , 


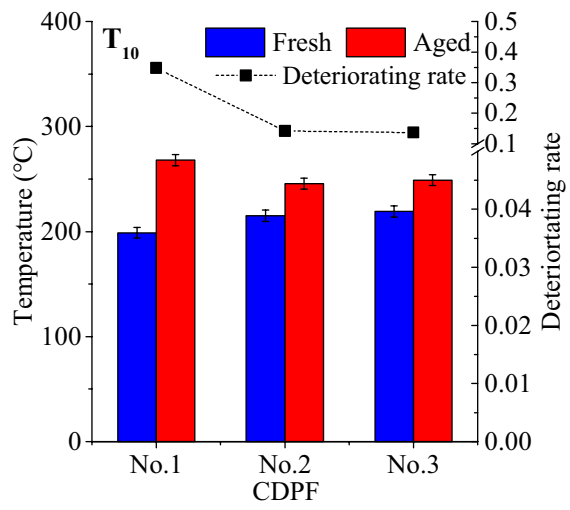

(a)

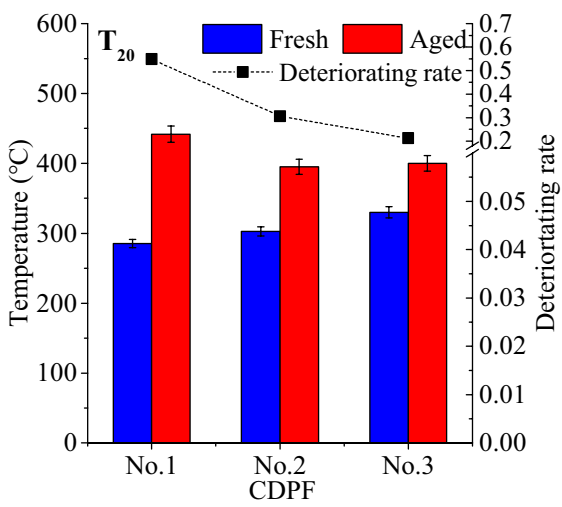

(b)

Figure 8. Characteristic temperatures and deteriorating rates of $10 \%$ and $20 \% \mathrm{NO}_{2}$ production rates (a) $10 \%$ $\mathrm{NO}_{2}$ production rate $-\mathrm{T}_{10}$, (b) $20 \% \mathrm{NO}_{2}$ production rate $-\mathrm{T}_{20}$.

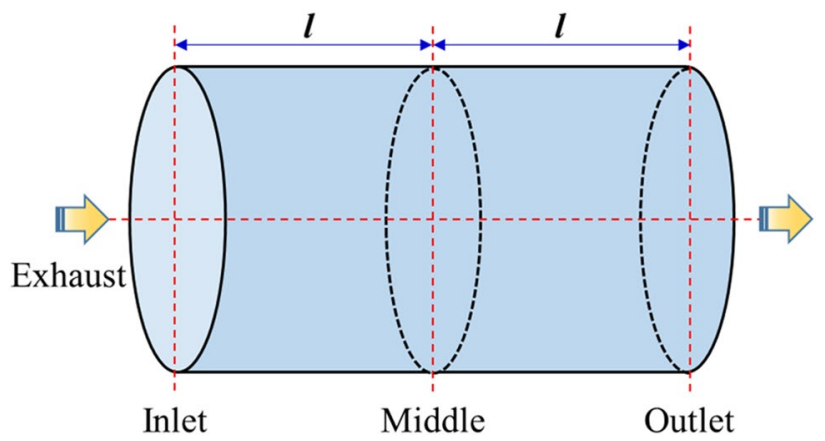

Figure 9. Diagram of the inlet, middle and outlet parts of the CDPF.

3.16 and 3.13. In terms of $\mathrm{T}_{50}$, the aging of CDPFs led to deteriorating rates of $0.45,0.31$ and 0.26 for No.1, No.2 and No.3 CDPFs. In general, the deteriorating rates decreased with the noble metal loadings of the CDPF, but the decline showed a decreasing trend.

Figure 8 shows the characteristic temperatures and deteriorating rates of $10 \%$ and $20 \% \mathrm{NO}_{2}$ production rates. The $\mathrm{T}_{10} \mathrm{~s}$ of the three CDPFs in fresh condition were about $200^{\circ} \mathrm{C}$ and they increased to $268.03,245.53$ and $249.16^{\circ} \mathrm{C}$, respectively after aging, with the deteriorating rates of $0.35,0.14$ and 0.14 . For $\mathrm{T}_{20}$ characteristics, the $60,000 \mathrm{~km}$ ' on-vehicle aging caused deteriorating rates of $0.55,0.31$ and 0.21 for No.1, No.2 and No.3 CDPFs. It can be seen that the deteriorating rates for $\mathrm{NO}_{2}$ production decreased with the noble metal loadings of the $\mathrm{CDPF}$, but the decline also showed a decreasing trend.

The aging performance of the different regions of CDPFs. Due to the gradient effect of airflow and exhaust temperature in CDPFs, the aging performance of different regions of CDPFs is different. In this part, No.2 CDPF after 60,000 km' aging was chose to study the aging performance of the inlet, middle and outlet parts as shown in Fig. 9 based on XRD, XPS and activity evaluation methods.

XRD and crystallinity analysis. Figure 10 shows the XRD diffraction patterns of inlet, middle and outlet parts of the CDPF with catalyst loading of $0.71 \mathrm{~g} / \mathrm{L}$ after $60,00 \mathrm{~km}$ ' aging. It can be seen that the XRD diffraction patterns were similar for the three parts. The characteristic diffraction peaks (marking a, b, c) all occurred in the ranges of $10^{\circ}-11^{\circ}, 17^{\circ}-22^{\circ}$ and $25^{\circ}-31^{\circ}$. From the local enlargements, it can be seen that the characteristic diffraction peaks shifted towards larger angles after aging, and the offsets for the inlet and middle parts were larger, while the outlet was not remarkable.

Figure 11 presents the crystallinity of the inlet, middle and outlet regions of the No. 2 CDPF with catalyst loading of $0.71 \mathrm{~g} / \mathrm{L}$ after $60,000 \mathrm{~km}$ ' aging. The crystallinity increased from $76.15 \%$ to $79.50 \%$ for the inlet region. While for the middle and outlet regions, the crystallinity increased to $78.30 \%$ and $79.22 \%$, respectively. It can be seen that the crystallinity of the inlet region was highest, followed by the outlet region and the middle region was the smallest. The increase of crystallinity is mainly caused by the sintering of noble metals and metal oxides and the formation of agglomerates with poor crystalline phase ${ }^{40}$. 


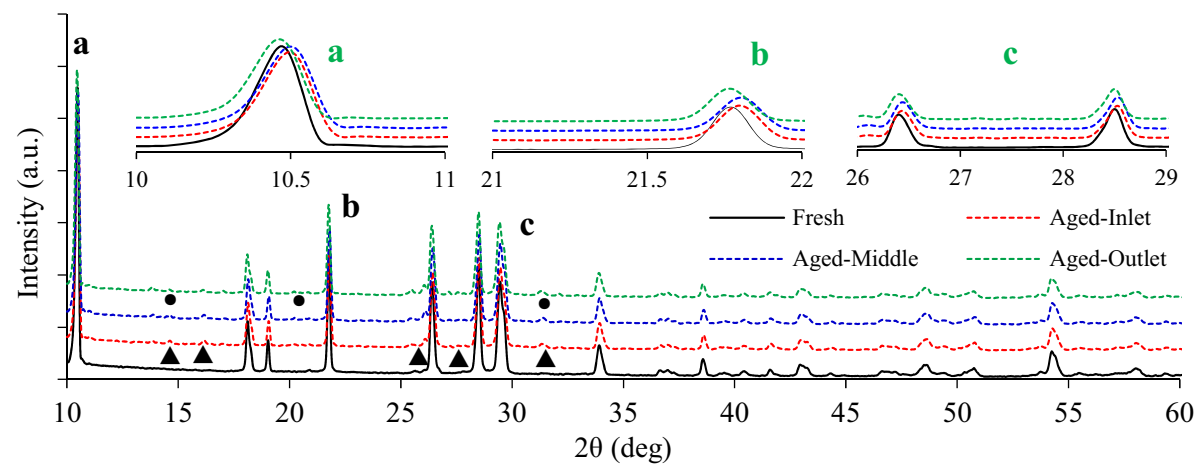

Figure 10. XRD results of different regions of CDPF after aging.

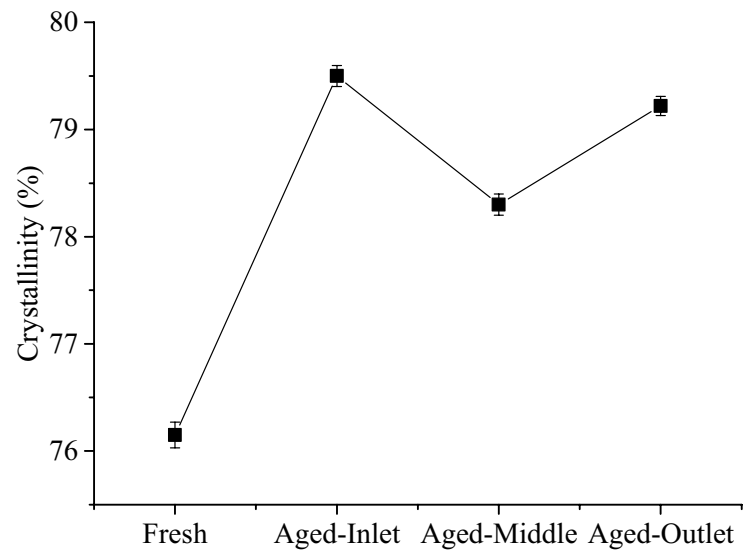

Figure 11. Crystallinity of the inlet, middle and outlet regions of CDPF after aging.

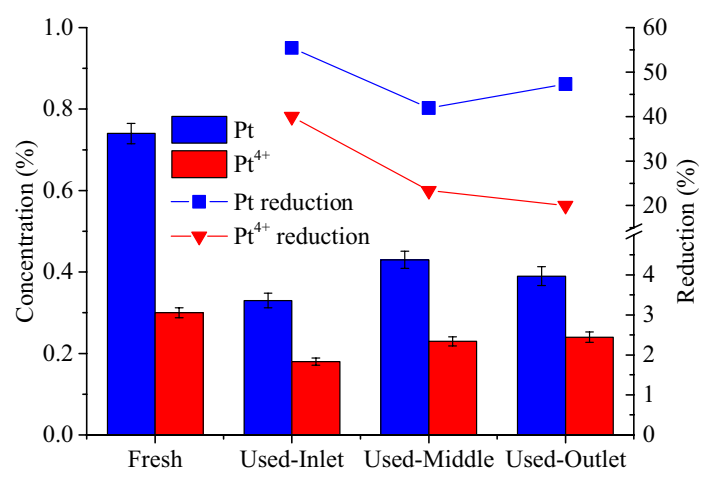

Figure 12. $\mathrm{Pt}$ and $\mathrm{Pt}^{4+}$ concentrations and reduction in different regions of CDPFs after aging.

Active element and valence states analysis. Figure 12 presents the $\mathrm{Pt}$ and $\mathrm{Pt}^{4+}$ concentrations of the inlet, middle and outlet regions of the CDPF measured by XPS. It can be seen that aging led to a remarkable decrease of the Pt and $\mathrm{Pt}^{4+}$ concentrations. For the inlet region of the CDPF, the Pt concentration decreased from $0.74 \%$ to $0.33 \%$ with a reduction of $55.4 \%$ after aging. In terms of the Pt concentration reduction, the inlet region was highest, and the outlet and the middle region followed. It was also obtained that aging caused a $40.00 \%$ reduction of the $\mathrm{Pt}^{4+}$ concentration in the inlet region. While for middle and outlet regions, the reductions reached $23.30 \%$ and $20.01 \%$, respectively. The main reason is that the CDPF aging led to agglomeration and sintering of the noble metal catalyst on the carrier, resulting in a reduction in the main active components such as $\mathrm{Pt}$ and $\mathrm{Pt}^{4+41}$. However, the inlet part of CDPF is always subject to higher exhaust temperature of the diesel engine compared with other parts of the CDPF, the thermal aging degree is deeper, therefore leading to larger reduction in the Pt and $\mathrm{Pt}^{4+}$ concentration. Although the outlet part of the CDPF bears the minimum heat load of the diesel engine, the 


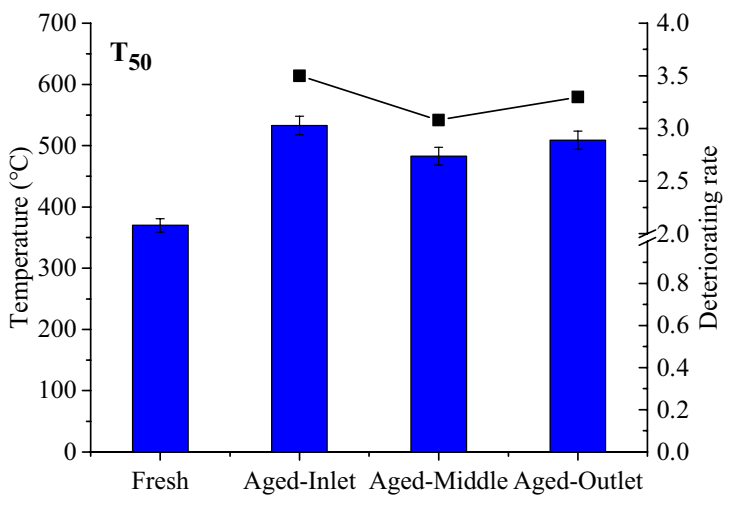

(a)

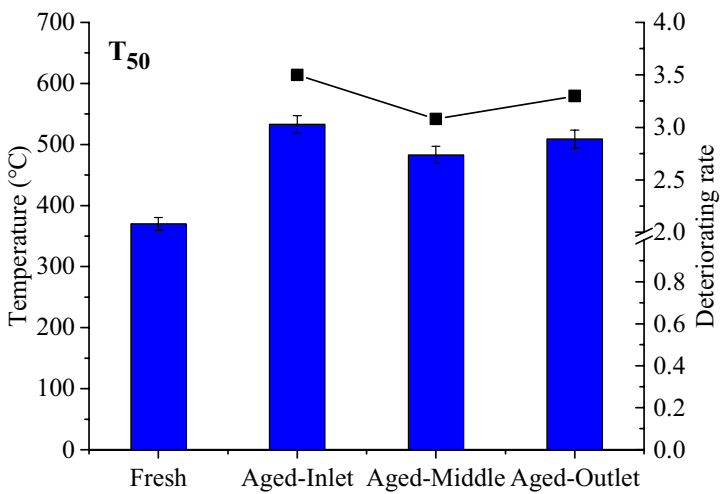

(b)

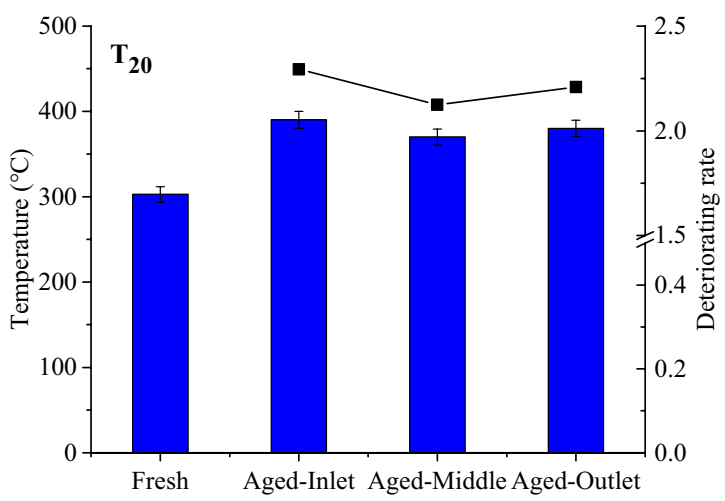

(c)

Figure 13. Characteristic temperatures and deteriorating rates of $\mathrm{CO}, \mathrm{C}_{3} \mathrm{H}_{8}$ conversion rates and $\mathrm{NO}_{2}$ production rate in different regions after aging, (a) $\mathrm{CO},(\mathbf{b}) \mathrm{C}_{3} \mathrm{H}_{8},(\mathbf{c}) \mathrm{NO}_{2}$.

soot trapped by the CDPF are concentrated in this part, and the oxidation of the soot will release heat, which deepens thermal aging of the CDPF outlet ${ }^{42}$. In comparison, the middle part of the CDPF bears the minimum heat load, the thermal aging degree is the least, causing a smaller reduction in the Pt concentration compared with those of inlet and outlet parts of the CDPF.

Catalytic activity evaluation. Figure 13 depicts the characteristic temperatures and deteriorating rates of $\mathrm{CO}$, $\mathrm{C}_{3} \mathrm{H}_{8}$ conversion rates and $\mathrm{NO}_{2}$ production rate in different regions of the CDPF after aging. It can be observed from Fig. 13a that $\mathrm{T}_{50} \mathrm{~s}$ of $\mathrm{CO}$ conversion in different regions of the CDPF after aging increased and the deteriorating rates of the inlet, outlet and middle regions were $0.67,0.62$ and 0.55 . In terms of $\mathrm{T}_{50} \mathrm{~S}$ of $\mathrm{C}_{3} \mathrm{H}_{8}$ conversion, they increased to above $500{ }^{\circ} \mathrm{C}$ after aging for all the three regions, much higher than that in fresh condition. The deteriorating rates of the inlet, middle and outlet regions were 3.50, 3.30 and 3.08 respectively. Figure $13 \mathrm{c}$ shows that aging increased the $\mathrm{T}_{20} \mathrm{~s}$ of $\mathrm{NO}_{2}$ production and brought about deteriorating rates of 2.29, 2.21 and 2.12 for the inlet, middle and outlet regions of CDPF.

It can be concluded that the inlet, middle and outlet parts of the CDPF shown different aging performance. The deteriorating rate of the inlet region was the highest, the following is the outlet region and the middle region was the smallest. The main reason was that the inlet region of the CDPF was nearest to the diesel engine, longtime in the higher-temperature exhaust accelerated the thermal deactivation. On the contrary, the exhaust temperature in the outlet region was relatively low, meaning less thermal deactivation ${ }^{43}$. However, the trapped soot in the CDPF was stacked in the outlet region due to the influence of the exhaust flow, where higher temperature would occur when the regeneration happened of the CDPF, which would accelerate the thermal deactivation of the catalyst in this region. The thermal load in the middle region of the CDPF was relatively low, resulting in less thermal deactivation compared to the other two regions.

Microstructure and composition of the soot and ash in CDPFs with different aging mileage. In this part, the ash and soot in the No.2 CDPF was sampled and analyzed after 30,000 and 60,000 km' using.

Microstructure of the soot and ash. Figure 14 shows scanning electron microscope (SEM) images of mixtures of soot and ash and the ash after the combustion of the mixture in CDPFs with different aging mileage with a magnification of 1000. It can be seen from Fig. 14a that the aggregates of the soot and ash in the CDPF after $30,000 \mathrm{~km}$ ' aging consisted of irregular lumps of particles. The aggregates were large and arranged loosely with 


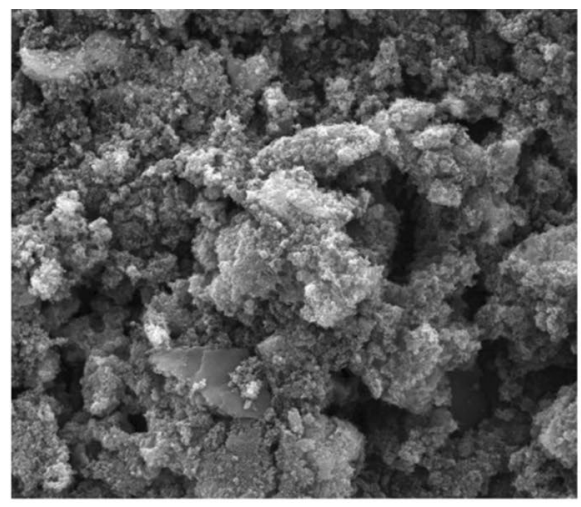

(a)

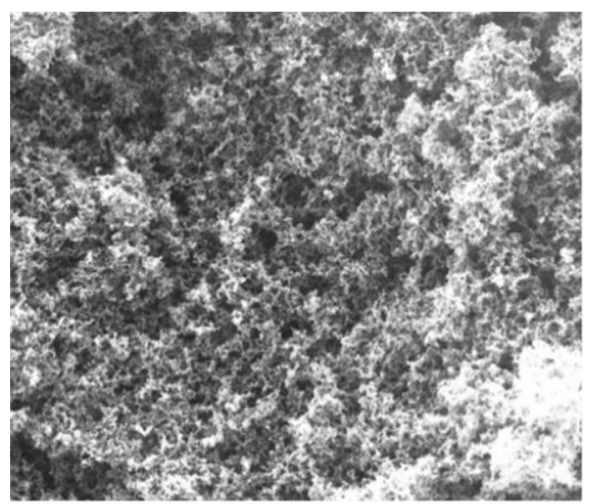

(c)

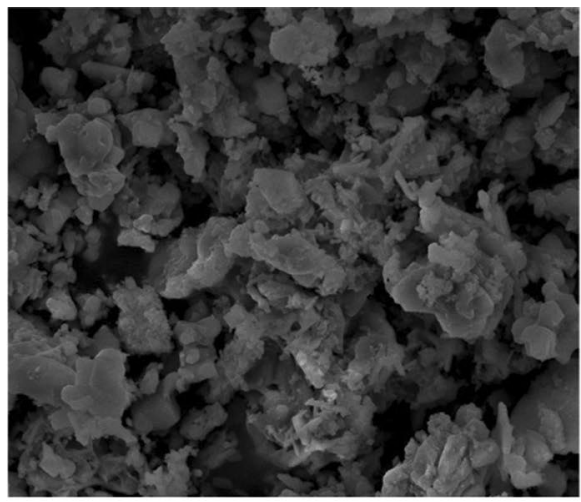

(b)

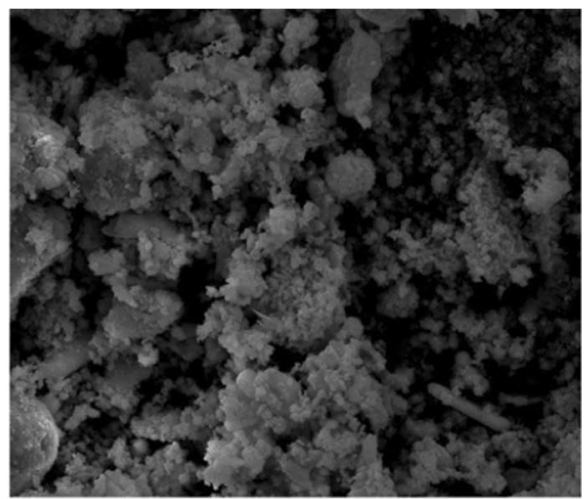

(d)

Figure 14. Microstructure of the soot and ash in the CDPF with different aging mileage, (a) soot and ash in the CDPF after 30,000 km' aging, (b) ash after combustion in the CDPF after 30,000 km' aging, (c) soot and ash in the CDPF after 60,000 km' aging, (d) ash after combustion in the CDPF after 60,000 km' aging.

obvious porous structures in between. Figure $14 \mathrm{~b}$ shows the image of the ash of the mixture of soot and ash after combustion. It can be seen that the ash is comprised of irregular, smooth and lamellar or blocky particles, and the aggregates in the ash were small, in which the particles arranged closer. Figure $14 \mathrm{c}$ shows the image of the aggregates of soot and ash in the CDPF after 60,000 km' aging. The aggregates were small with flocculent, porous surface and arranged closely each other. Figure $14 \mathrm{~d}$ shows the image of the soot and ash mixture in the $60,000 \mathrm{~km}$ ' aging CDPF after combustion. The ash was clustered by irregular, globular particles and the aggregates were small and arranged more closely than that of $30,000 \mathrm{~km}$ aging.

Composition of the soot and ash in CDPFs with different aging mileage. Figure 15 presents the composition and atom content of the soot and ash in CDPFs with different aging mileage by energy dispersive spectrometer (EDS) test. The composition of the soot and ash in the CDPF mainly included $\mathrm{C}, \mathrm{O}$ and $\mathrm{S}$, in which $\mathrm{C}$ and $\mathrm{O}$ accounted for $80.78 \%$ and $13.35 \%$ respectively after $30,000 \mathrm{~km}$ aging. For the soot and ash in the CDPF after $60,000 \mathrm{~km}$ ' aging, $\mathrm{C}$ and $\mathrm{O}$ accounted for $83.24 \%$ and $10.18 \%$ respectively. It can be seen that the proportion of $\mathrm{C}$ increased with the aging mileage, which can be attributed to the fact that the deepening deterioration of the catalytic performance weakened the regeneration ability of the CDPF, leaving more soot unburned ${ }^{30}$. In terms of the S content, it reached $1.29 \%$ in the soot and ash mixture after 30,000 km' aging of the CDPF, while after $60,000 \mathrm{~km}$ ' aging, the $\mathrm{S}$ content in the soot and ash mixture increased to $3.66 \%$. When cleaning the ash and soot, the $\mathrm{S}$ content in the CDPF substrate remained $0.54 \%$. Although the $\mathrm{S}$ content in the mixture of ash and soot increased about 3 times, the $S$ content absorbed in the CDPF was very low, indicating that the CDPF has a certain tolerance to $\mathrm{S}$.

\section{Conclusions}

The effects of noble metal loadings and different regions on the aging performance of the CDPF's catalytic property were studied using XRD, XPS and catalytic activity evaluation methods based on on-vehicle durability condition. Meanwhile, the effect of aging mileage on the microstructure and composition of the soot and ash in the CDPF was also investigated by SEM and EDS. The main conclusions are listed below:

1. The characteristic diffraction peaks of XRD patterns shifted towards larger angles and the crystallinity increased after aging of the CDPF. Besides, aging resulted in a decline of the $\mathrm{Pt}$ and $\mathrm{Pt}^{4+}$ concentrations on 


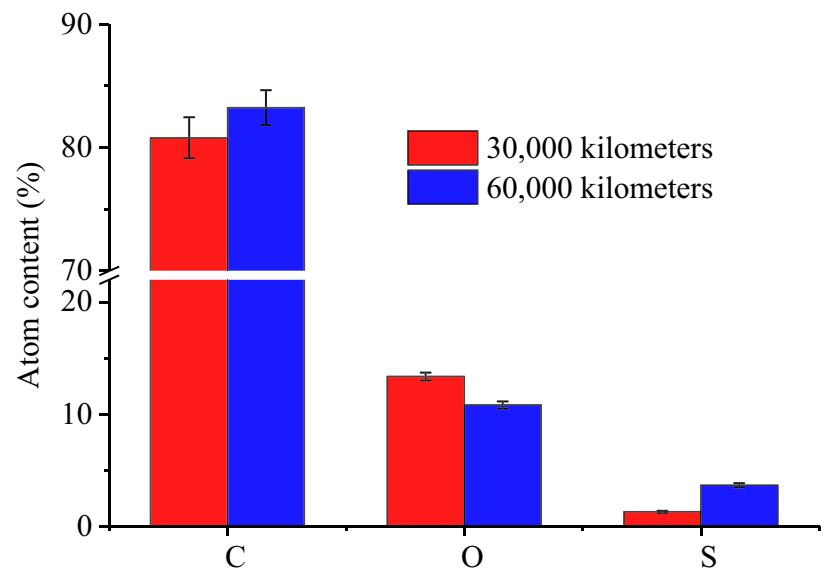

Figure 15. Composition and atom content of the soot and ash in CDPFs with different aging mileage.

the CDPF surface, as well as an increase of the characteristic temperatures of $\mathrm{CO}, \mathrm{C}_{3} \mathrm{H}_{8}$ conversion and $\mathrm{NO}_{2}$ production.

2. The noble metal loadings had significant influence on the aging performance of the CDPF. The incremental crystallinity caused by aging shown a slowdown with the increase of the noble metal loadings. And the effect of noble metal loadings on $\mathrm{Pt}$ and $\mathrm{Pt}^{4+}$ concentrations changing during aging was the same as that of crystallinity. In addition, the increase of characteristic temperatures of $\mathrm{CO}, \mathrm{C}_{3} \mathrm{H}_{8}$ conversion and $\mathrm{NO}_{2}$ production caused by aging presented a downward trend with the noble metal loadings. The anti-aging ability of the CDPF's catalytic performance was proportional to the noble metal loadings, but noticeably, excessive amounts of noble metals would not have the corresponding anti-aging properties. Consequently, considering the cost and performance, No.2 CDPF was the best choice of the three.

3. The aging performance of the CDPF in different regions was different. After $60,000 \mathrm{~km}$ ' aging, the crystallinity in the inlet region was the highest while the $\mathrm{Pt}$ and $\mathrm{Pt}^{4+}$ concentrations was the lowest compared with that in the middle and outlet regions. In addition, the characteristic temperatures of $\mathrm{CO}, \mathrm{C}_{3} \mathrm{H}_{8}$ conversion and $\mathrm{NO}_{2}$ production were higher than the other two regions. The degree of aging in the inlet region was the deepest, followed by the outlet region and the middle region was the smallest.

4. The increase of aging mileage reduced the size of the aggregates of the soot and ash in the CDPF while increased degree of tightness between particles. The deepening of the CDPF aging could be reflected by the increase of $\mathrm{C}$ concentration in the soot and ash.

Received: 3 August 2020; Accepted: 26 October 2020

Published online: 13 November 2020

\section{References}

1. Yessian, S. \& Varthanan, P. A. Optimization of performance and emission characteristics of catalytic coated ic engine with biodiesel using grey-taguchi method. Sci. Rep. 10(1), 1-13 (2020).

2. Alptekin, E. Evaluation of ethanol and isopropanol as additives with diesel fuel in a CRDI diesel engine. Fuel 205, 161-172 (2017).

3. Senecal, P. K. \& Leach, F. Diversity in transportation: Why a mix of propulsion technologies is the way forward for the future fleet. Results Eng. 4, 100060 (2019).

4. Rousseau-Ralliard, D. et al. Effects of first-generation in utero exposure to diesel engine exhaust on second-generation placental function, fatty acid profiles and foetal metabolism in rabbits: preliminary results. Sci. Rep. 9(1), 1-15 (2019).

5. Ithnin, A. M. et al. Emulsifier-free Water-in-Diesel emulsion fuel: Its stability behaviour, engine performance and exhaust emission. Fuel 215, 454-462 (2018).

6. Nayyar, A., Sharma, D., Soni, S. L. \& Mathur, A. Characterization of n-butanol diesel blends on a small size variable compression ratio diesel engine: modeling and experimental investigation. Energy Convers. Manag. 150, 242-258 (2017).

7. Zhang, Y., Lou, D., Tan, P. \& Hu, Z. Experimental study on the particulate matter and nitrogenous compounds from diesel engine retrofitted with DOC+ CDPF+ SCR. Atmos. Environ. 177, 45-53 (2018).

8. Du, Y. et al. Characterization of soot deposition and oxidation process on catalytic diesel particulate filter with ash loading through an optimized visualized method. Fuel 243, 251-261 (2019).

9. Kong, H. \& Yamamoto, K. Simulation on soot deposition in in-wall and on-wall catalyzed diesel particulate filters. Catal. Today 332, 89-93 (2019).

10. Zhang, Y. et al. Emission reduction characteristics of a catalyzed continuously regenerating trap after-treatment system and its durability performance. J. Environ. Sci. 84, 166-173 (2019).

11. Jiao, P. et al. Research of DPF regeneration with NOx-PM coupled chemical reaction. Appl. Therm. Eng. 110, 737-745 (2017).

12. Nascimento, L. F. et al. Control of diesel particulate emission based on $\mathrm{Ag} / \mathrm{CeOx} / \mathrm{FeOy}$ catalysts supported on cordierite. Chem. Eng. J. 290, 454-464 (2016).

13. Gao, J. et al. Oxidation activity restoration of diesel particulate matter by aging in air. Energy Fuels 32(2), 2450-2457 (2018).

14. Liu, Y. et al. Chemical deactivation of commercial vanadium SCR catalysts in diesel emission control application. Chem. Eng. J. 287, 680-690 (2016).

15. Lupše, J., Campolo, M. \& Soldati, A. Modelling soot deposition and monolith regeneration for optimal design of automotive DPFs. Chem. Eng. Sci. 151, 36-50 (2016). 
16. Guan, B., Zhan, R., Lin, H. \& Huang, Z. Review of the state-of-the-art of exhaust particulate filter technology in internal combustion engines. J. Environ. Manag. 154, 225-258 (2015).

17. Kleinhenz, M., Fiedler, A., Lauer, P. \& Döring, A. SCR coated DPF for marine engine applications. Top Catal. 62(1-4), 282-287 (2019).

18. Ercolino, G., Karimi, S., Stelmachowski, P. \& Specchia, S. Catalytic combustion of residual methane on alumina monoliths and open cell foams coated with $\mathrm{Pd} / \mathrm{Co}_{3} \mathrm{O}_{4}$. Chem. Eng. J. 326, 339-349 (2017).

19. Choi, B., Liu, B. \& Jeong, J. W. Effects of hydrothermal aging on SiC-DPF with metal oxide ash and alkali metals. J. Ind. Eng. Chem. 15(5), 707-715 (2009).

20. Liu, Y., Xu, X., Wang, J. M. \& Shi, F. L. Research on performance of ultra-low precious metal catalyst for diesel engine vehicle. Trans. CSICE S1, 31-34 (2008).

21. Zhang, J., Lou, D. M., Tan, P. Q. \& Zhao, K. X. Particle emissions characteristics of diesel bus with different after-treatment. J. Tongji Univ. (Nat. Sci.) 46(7), 956-963. https://doi.org/10.11908/j.issn.0253-374x.2018.07.014 (2018).

22. Liu, H. Q., Gao, Y., Fang, M., Chen, W. \& Li, Y. A research on the effects of coating amount on the pressure drops and regeneration characteristics of CDPF. Automot. Eng. 38(7), 800-804. https://doi.org/10.19562/j.chinasae.qcgc.2016.07.002 (2016).

23. Tsuda, T., Miura, K., Hikasa, A., Hosoi, K. \& Kimata, F. Improvement of the thermal durability of an exhaust gas purifying catalyst using size-controlled PT-hydroxide clusters. SAE Int. J. Engines 9(4), 2442-2450 (2016).

24. Hauff, K., Tuttlies, U., Eigenberger, G. \& Nieken, U. A global description of DOC kinetics for catalysts with different platinum loadings and aging status. Appl. Catal. B Environ. 100(1), 10-18 (2010).

25. Ren, X., Li, Z. \& Liu, S. Influence of noble metal contents on catalytic performance of the catalysts for sulfur and hydrothermal tolerance. Ind. Catal. 21(11), 36-40 (2013).

26. Ahari, H., Zammit, M., Cattani, L., Jacques, J. \& Pauly, T. Cause and effect of reversible deactivation of diesel oxidation catalysts. Report No. 2014-01-1518, (SAE Technical Paper, 2014). https://doi.org/10.4271/2014-01-1518

27. Zhan, R., Eakle, S., Spreen, K., Li, C. G. \& Mao, F. F. Validation method for diesel particulate filter durability. Report No. 2007-014086, (SAE Technical Paper, 2007). https://doi.org/10.4271/2007-01-4086

28. Bai, S., Wang, C., Li, D., Wang, G. \& Li, G. Influence of the idle-up strategy on the thermal management of diesel particulate filter regeneration during a drop to the idle process. Appl. Therm. Eng. 141, 976-980 (2018).

29. Preble, C. V., Cados, T. E., Harley, R. A. \& Kirchstetter, T. W. In-use performance and durability of particle filters on heavy-duty diesel trucks. Environ. Sci. Technol. 52(20), 11913-11921 (2018).

30. Bagi, S., Sharma, V., Patel, M. \& Aswath, P. B. Effects of diesel soot composition and accumulated vehicle mileage on soot oxidation characteristics. Energy Fuels 30(10), 8479-8490 (2016).

31. Zhang, Y., Lou, D., Tan, P. \& Hu, Z. Experimental study on the emission characteristics of a non-road diesel engine equipped with different after-treatment devices. Environ. Sci. Pollut. Res. 26(26), 26617-26627 (2019).

32. Huang, H., Zhang, X., Liu, J. \& Ye, S. Study on oxidation activity of ce-Mn-K composite oxides on diesel soot. Sci. Rep. 10(1), 1-10 (2020).

33. Corro, G. et al. Electronic state of silver in $\mathrm{Ag} / \mathrm{SiO}_{2}$ and $\mathrm{Ag} / \mathrm{ZnO}$ catalysts and its effect on diesel particulate matter oxidation: an XPS study. Appl. Catal. B Environ. 216, 1-10 (2017).

34. Ozawa, M. et al. Low content Pt-doped $\mathrm{CeO}_{2}$ and core-shell type $\mathrm{CeO}_{2} / \mathrm{ZrO}_{2}$ model catalysts; microstructure, TPR and three way catalytic activities. Catal. Today 332, 251-258 (2019).

35. Yamazaki, K., Sakakibara, Y., Dong, F. \& Shinjoh, H. The remote oxidation of soot separated by ash deposits via silver-ceria composite catalysts. Appl. Catal. A Gen. 476, 113-120 (2014).

36. Mihai, O., Stenfeldt, M. \& Olsson, L. The effect of changing the gas composition on soot oxidation over DPF and SCR-coated filters. Catal. Today 306, 243-250 (2018).

37. Rategarpanah, A., Meshkani, F., Wang, Y., Arandiyan, H. \& Rezaei, M. Thermocatalytic conversion of methane to highly pure hydrogen over Ni-Cu/MgO$\cdot \mathrm{Al}_{2} \mathrm{O}_{3}$ catalysts: Influence of noble metals ( $\mathrm{Pt}$ and $\mathrm{Pd}$ ) on the catalytic activity and stability. Energy Convers. Manag. 166, 268-280 (2018).

38. Holzwarth, U. \& Gibson, N. The Scherrer equation versus the 'Debye-Scherrer equation'. Nat. Nanotechnol. 6(9), 534-534 (2011).

39. Liang, Y., Ding, X., Zhao, M., Wang, J. \& Chen, Y. Effect of valence state and particle size on NO oxidation in fresh and aged Ptbased diesel oxidation catalysts. Appl. Surf. Sci. 443, 336-344 (2018).

40. Goodman, E. D. et al. Catalyst deactivation via decomposition into single atoms and the role of metal loading. Nat. Catal. 2(9), 748-755 (2019).

41. Zhang, B. et al. Influence of structural and operating factors on performance degradation of the diesel particulate filter based on composite regeneration. Appl. Therm. Eng. 121, 838-852 (2017).

42. Pechout, M. et al. Comparison of hydrogenated vegetable oil and biodiesel effects on combustion, unregulated and regulated gaseous pollutants and DPF regeneration procedure in a Euro6 car. Sci. Total Environ. 696, 133748.1-133748.14 (2019).

43. Deng, Y. et al. Investigations on the temperature distribution of the diesel particulate filter in the thermal regeneration process and its field synergy analysis. Appl. Therm. Eng. 123, 92-102 (2017).

\section{Acknowledgements}

This work was supported by the National Key R\&D Program of China (No. 2017YFE0102800).

\section{Author contributions}

Y.H.Z. and D.M. Lou conceptualized the methodology and conducted all the experiments; D.M.L. provided the resources; Y.H.Z. performed the data analysis and processing, wrote and prepared the original manuscript. Y.H.Z., P.Q.T. and Z.Y.H. revised the manuscript.

\section{Competing interests}

The authors declare no competing interests.

\section{Additional information}

Correspondence and requests for materials should be addressed to Y.Z. or D.L.

Reprints and permissions information is available at www.nature.com/reprints.

Publisher's note Springer Nature remains neutral with regard to jurisdictional claims in published maps and institutional affiliations. 
(c) (i) Open Access This article is licensed under a Creative Commons Attribution 4.0 International cc) License, which permits use, sharing, adaptation, distribution and reproduction in any medium or format, as long as you give appropriate credit to the original author(s) and the source, provide a link to the Creative Commons licence, and indicate if changes were made. The images or other third party material in this article are included in the article's Creative Commons licence, unless indicated otherwise in a credit line to the material. If material is not included in the article's Creative Commons licence and your intended use is not permitted by statutory regulation or exceeds the permitted use, you will need to obtain permission directly from the copyright holder. To view a copy of this licence, visit http://creativecommons.org/licenses/by/4.0/.

(C) The Author(s) 2020 